\title{
Percepção da família acerca do suporte profissional recebido em um serviço de saúde mental
} infanto-juvenil

\section{Perception of the family about the professional support received in a children and adolescents' mental health servisse}

\section{Percepción de la familia sobre el apoyo profesional recibido en un servicio de salud mental infantojuvenil}

Recebido: 20/11/2019

Aprovado: 22/04/2020

Publicado: 01/08/2020

\author{
Ingrid Moreira dos Santos ${ }^{1}$ \\ Belisa Vieira da Silveira ${ }^{2}$ \\ Adaene Alves Machado de Moura ${ }^{3}$ \\ Sandra Cristina Pillon ${ }^{4}$
}

Este é uma pesquisa qualitativa realizada em Belo Horizonte/MG, ocorrida no primeiro semestre de 2018, com o objetivo de conhecer a percepção da família sobre o suporte profissional recebido em um serviço de saúde mental infanto-juvenil. Os dados foram coletados por entrevista com roteiro semiestruturado e os dados foram analisados por meio da análise de conteúdo proposta por Bardin. Participaram nove familiares de adolescentes em tratamento e três profissionais de saúde. Três categorias foram construídas: Transtorno mental e Adolescência, Transtorno mental e Família e, Tratamento oferecido ao familiar no serviço. Os familiares relatam que gostariam que o serviço desenvolvesse atividades de escuta com mais frequência, uma vez que se sentiam fragilizados e receosos a respeito da condição clínica do adolescente. Em contrapartida, os profissionais de saúde realizam poucos encontros com os familiares devido à sobrecarga de trabalho. Percebe-se a necessidade de ações e atendimentos mais frequentes direcionados aos familiares para aliviar as angústias decorrentes do transtorno mental do adolescente em tratamento.

Descritores: Serviços de saúde mental; Adolescente; Família.

This is a qualitative research carried out in Belo Horizonte/MG, Brazil, which took place in the first semester of 2018, with the objective of researching the family's perception of the professional support received in a children's mental health service. The data were collected by means of an interview with a semi-structured script and analyzed by using the content analysis proposed by Bardin. Nine family members of adolescents undergoing treatment and three health professionals have participated in the study. Three categories were constructed: Mental disorder and Adolescence, Mental disorder and Family and Treatment offered to the family member at the service. Family members reported that they would like the service to develop listening activities more frequently, since they felt fragile and feared the adolescent's clinical condition could deteriorate. In contrast, it has been noticed that the health professionals usually have few meetings with family members due to work overload. The need for more frequent actions and assistance directed to family members is perceived to alleviate the anguish resulting from the mental disorder of the adolescent being treated.

Descriptors: Mental health services; Adolescent; Family.

Esta es una investigación cualitativa llevada a cabo en Belo Horizonte/MG, Brasil, ocurrida en el primer semestre de 2018, con el objetivo de conocer la percepción de la familia sobre el apoyo profesional recibido en un servicio de salud mental infantojuvenil. Los datos se recopilaron mediante entrevista con un guión semiestructurado y los datos se analizaron utilizando el análisis de contenido propuesto por Bardin. Participaron nueve familiares de adolescentes sometidos a tratamiento y tres profesionales de la salud. Se construyeron tres categorías: trastorno mental y adolescencia, trastorno mental y familia y tratamiento ofrecido al miembro de la familia en el servicio. Los miembros de la familia informan que les gustaría que el servicio desarrollara actividades de escucha con mayor frecuencia, ya que se sentían frágiles y temerosos sobre la condición clínica del adolescente. En contraste, los profesionales de la salud tienen pocas reuniones con miembros de la familia debido a la sobrecarga de trabajo. Se percibe la necesidad de acciones y asistencia más frecuentes dirigidas a los miembros de la familia para aliviar la angustia resultante del trastorno mental del adolescente que está siendo tratado.

Descriptores: Servicios de salud mental; Adolescente; Familia.

1. Acadêmica do curso de Graduação Enfermagem pela Faculdade de Ensino de Minas Gerais, Belo Horizonte, MG, Brasil. ORCID: 0000-0002-8287-673X E-mail: moreiraingrid57@gmail.com

2. Enfermeira. Especialista em Saúde Mental na Prática Contemporânea. Especialista em Docência e Gestão do Ensino Superior. Mestre em Saúde e Enfermagem. Doutoranda Programa de Pós-Graduação em Enfermagem Psiquiátrica (PPGEP) da Escola de Enfermagem de Ribeirão Preto da Universidade de São Paulo (EERP-USP), SP, Brasil. ORCID: 0000-0002-5966-8537 E-mail: belisavsilveira@gmail.com

3 Enfermeira. Especialista em Prevenção do Uso Indevido de Drogas. Mestre em Ciências da Saúde. Doutoranda Pelo PPGEP-EERP-USP, SP, Brasil. ORCID: 0000-0001-7607-9841 E-mail: adaene_moura@hotmail.com

4 Enfermeira. Especialista em Dependência Química. Mestre em Gastroenterologia. Doutora em Psiquiatria e Psicologia Médica. Professora Titular do PPGEP-EERP-USP, SP, Brasil. ORCID: 0000-0001-8902-7549. E-mail: pillon@eerp.usp.br 


\section{INTRODUÇÃO}

A

Adolescência é um período do ciclo vital marcado por significativas mudanças fisiológicas, psicológicas e comportamentais e/ou relacionais, no qual um indivíduo, a partir de suas vivências, vai construindo a sua identidade e subjetividade ${ }^{1,2}$. Em contrapartida às experimentações inerentes à adolescência, associadas à busca por prazer e aceitação social, existe uma imaturidade biológica para a avaliação da tomada de decisão e das possíveis consequências, o que fazem desse período uma fase de vulnerabilidade biopsicossocial, com ou sem sofrimento psíquico transitório ou permanente ${ }^{2,3}$.

De acordo com dados da Organização Mundial de Saúde (OMS) um em cada cinco adolescentes apresenta problemas relacionados à saúde mental, sendo que metade de todos os transtornos mentais são desencadeados ainda na adolescência, em torno dos 14 anos ${ }^{4}$. Além disto, quanto mais cedo ocorre o primeiro surto psicótico, maior será a gravidade do sofrimento e o impacto nos aspectos da vida no indivíduo, o que demanda acompanhamento do mesmo e da sua família ${ }^{5,6}$.

Na adolescência, por si só, ocorrem alterações na dinâmica familiar, uma vez que as normas e relações precisam ser reajustadas frente às novas demandas e à crescente autonomia do jovem ${ }^{7}$. Estudo evidencia que essa reconfiguração familiar e os conflitos, bem como, medidas muito impositivas e inflexíveis muitas vezes estão associadas a problemas de saúde mental entre os adolescentes ${ }^{8}$.

Nas famílias em que as relações conflituosas pré existem, o surgimento da doença na criança ou adolescente faz com que a teia de problemas se intensifique, agravando o processo de adoecimento ${ }^{9}$. Assim, o processo da doença na família, inevitavelmente, contribui para o desencadeamento de desequilíbrios nas relações familiares. Na maioria das vezes, o adoecimento mental de um ente desperta na família vários sentimentos negativos, como culpa, raiva, incompetência, medo, insegurança, vergonha, dentre outros. Além disso, a família ainda precisa manejar os sintomas relacionados ao transtorno mental, adequar-se à nova rotina de medicamentos e consultas em serviços especializados, o que impacta na vida social dos cuidadores $^{8-10}$.

Não obstante, familiares de pessoas com portadores de transtornos mentais buscam pela hospitalização e/ou institucionalização temporária do indivíduo, refletindo a sobrecarga no cuidado, sendo a hospitalização um alívio e descanso, quando o dia a dia se torna insuportável. A rotina cotidiana na vivência com um sujeito em crise, sem tratamento adequado, ocasiona esgotamentos físico e psíquico, também nos familiares ${ }^{8}$.

Nesse sentido, tornar-se um cuidador em saúde mental de um adolescente implica em sofrimentos psíquico associados, devido ao: caráter crônico da doença, estigmas fortemente vinculados ao transtorno mental, pouco conhecimento acerca da doença e, frequentemente, o baixo suporte social e profissional dos cuidadores ${ }^{11}$.

É importante que os serviços de saúde ofertem espaços de escuta e intervenção a familiares de adolescentes em sofrimento psíquico, uma vez que beneficia a saúde mental dos cuidadores e/ou familiares, o que potencializa a atuação na recuperação do indivíduo ${ }^{12}$. A cooperação entre serviço, profissional de saúde e família contribui positivamente para a reabilitação psicossocial, amenizando o sofrimento vivenciado por ambos durante 0 tratamento 13,14 .

A família tem potencial papel protetor, uma vez que se configura como o primeiro núcleo socializador do indivíduo. Famílias funcionais, que oferecem suporte afetivo e econômico à criança e adolescente são elementos relevantes para a manutenção da saúde mental e bem estar do indivíduo.

Aspectos comunitários, como envolvimento escolar, pertencimento a grupo de pares prosociais, acesso a serviços de saúde e cultura, bem como, características inerentes ao próprio adolescente (autoestima, abstinência do uso de substâncias psicoativas, autoconfiança e outros) são fatores de proteção ao desencadeamento precoce de transtornos mentais ${ }^{2,9}$. Assim, 
torna-se relevante promover abordagens aos adolescentes em sua completude, considerando os aspectos individuais, familiares e comunitários no processo saúde-doença.

No Brasil, a legislação vigente aborda os direitos e a proteção das pessoas que sofrem de transtorno mental, dispondo de atendimentos em saúde mental, de qualquer natureza, que devem ser direcionados à pessoa e seus familiares, além da assistência e a promoção de ações de saúde aos portadores de transtornos mentais com a devida participação da sociedade e da família ${ }^{15}$.

As unidades de acolhimento infanto-juvenil podem ser importantes dispositivos para minimizar o número de internações, que algumas vezes são desnecessárias, favorecendo o fortalecimento de ações de cuidado pautadas no direito ao convívio familiar e comunitário, reforçando o paradigma da inserção social para a promoção de saúde mental. Deste modo, recomenda-se que os serviços disponham de ações direcionadas às famílias do adolescente, para que essas não se sintam desamparadas ou perdidas em relação a como abordar e cuidar do jovem com transtorno mental ${ }^{16}$.

Apesar da legislação brasileira e as evidencias positivas sobre os benefícios bilaterais da inclusão da família na assistência às pessoas com transtorno mental, esta prática ainda não faz parte da rotina da maioria dos serviços de saúde mental, o que impacta na continuidade do tratamento e no prognóstico da doença, mas também, no cotidiano e na saúde mental do familiar cuidador ${ }^{14,17,18}$.

Com base nesses pressupostos, o presente estudo tem por objetivo conhecer as percepções de familiares acerca do suporte profissional recebido em serviço de saúde mental infanto-juvenil.

\section{MÉTODO}

Esta é uma pesquisa fundamentada na abordagem qualitativa, que consiste em uma investigação empírica de um fenômeno contemporâneo dentro de seu contexto na vida real, especialmente quando os limites entre o fenômeno e o contexto são multifacetados, envolvendo os aspectos sociais, psicológicos e comportamentais ${ }^{19}$.

A pesquisa foi desenvolvida em um serviço tradicional na assistência psiquiátrica infanto-juvenil de Belo Horizonte, Minas Gerais (MG), Brasil. 0 serviço foi fundado em 1947, vinculado à Fundação Hospitalar do Estado de Minas Gerais, considerado um centro de excelência de referência nacional na formação de profissionais da Rede Sistema Único de Saúde (SUS).

O serviço tem como missão assegurar e promover com excelência o acolhimento, o tratamento e a inclusão social de crianças e adolescentes, oferecendo assistência ambulatorial secundária e hospitalar aos usuários do Sistema Único de Saúde. As possibilidades terapêuticas oferecidas no referido serviço envolvem: urgência psiquiátrica, acompanhamento da crise, alojamento conjunto, leito-crise, permanência-dia, atendimento psicoterápico (individual e grupal), oficinas terapêuticas, ambulatório e lar abrigado, realizadas por equipe multiprofissional envolvendo psiquiatria, neurologia, psicologia, terapia ocupacional, serviço social, fonoaudiologia, enfermagem e fisioterapia.

Foram considerados para a pesquisa, os familiares acompanhando adolescentes internados ou em Permanência Dia (PD) há mais de duas semanas e foram excluídos, os familiares de adolescentes em primeira crise ou que apresentassem alteração cognitiva ou psicológica que impossibilitasse a participação.

Em relação aos profissionais, foram incluídos aqueles atuantes há mais de seis meses e excluídos os indivíduos que que estivessem afastados por motivo de férias ou de licença médica por período superior a 30 dias.

A equipe técnica da instituição forneceu uma lista contendo os nomes dos adolescentes que possuíam constantemente um acompanhante. Assim, entrevistou-se os familiares individualmente. Por ser um hospital referência, comumente foi observado jovens de diversas 
regiões do Estado de $\mathrm{MG}$, muitos sem acompanhantes, devido às diversas localidades de residência, assim como, adolescentes internados por mandado judicial, principalmente, por fatores psicossociais.

Os dados foram coletados no período de abril a junho de 2018, por meio de entrevista audiogravada com roteiro semiestruturado, mediante prévia autorização dos participantes. 0 material foi transcrito literalmente e na íntegra, constituindo o corpus de análise. A quantidade de participantes foi determinada pelo critério de saturação de dados ${ }^{20}$.

Os dados foram analisados e interpretados por meio de análise de conteúdo proposta por Bardin e, o conteúdo no processo analítico permitiu a construção de categorias temáticas ${ }^{21}$.

Para garantia do sigilo em relação à identidade dos participantes, atribuiu-se a cada um, conforme a ocorrência das entrevistas, a letra $\mathrm{F}$ para os participantes familiares e o mesmo critério para os profissionais de saúde a letra $\mathrm{P}$, acompanhada por sequência numérica (F1, F2, F3... e P1...).

Foram respeitados os pressupostos éticos em cumprimento à Resolução n. 466/2012 do Conselho Nacional de Saúde (CNS). A coleta de dados foi iniciada após a aprovação do Comitê de Ética e Pesquisa da Fundação Hospitalar do Estado de Minas Gerais sob CAAE no 60584516.2.0000.5119 e Parecer Consubstanciado no 1.772.544. Todos os participantes assinaram o Termo de Consentimento Livre e Esclarecido ${ }^{22}$.

\section{RESULTADOS}

O estudo foi realizado com nove familiares de adolescentes internados ou em PD e três profissionais de saúde do serviço (duas psicólogas e uma assistente social).

Dos nove familiares, sete eram mulheres, sendo o sexo feminino como o principal cuidador, com baixo nível de escolaridade, oito tinham o ensino fundamental incompleto e cinco eram provenientes de cidades do interior do Estado de MG. Quanto à faixa etária, dois familiares tinham idade entre 30 e 40 anos, quatro entre 41 a 50 anos, um entre 51 a 60 anos e dois tinham mais que 60 anos. Sete familiares afirmaram que tinham um outro membro na família com transtorno mental.

Apenas um familiar não afirmou a presença de um outro familiar com transtorno mental, no entanto relatou que um tio do adolescente internado apresentava alterações comportamentais graves, mas não havia diagnóstico definido. Quanto às modalidades para o tratamento no serviço, seis familiares acompanhavam os adolescentes em sua internação hospitalar e os demais jovens na assistência em PD.

Dos profissionais entrevistados, todos eram do sexo feminino, com formação acadêmica há mais de 10 anos e atuavam no serviço cerca de um ano e 6 meses. Nota-se, que possuíam formação e tempo de trabalho adequaılo que lhes permitiam responder sobre a dinâmica de funcionamento do serviço e a assistência à família na saúde mental. A princípio, a pesquisa tinha o intuito de entrevistar também os técnicos de referência (TR) desses adolescentes, conforme preconizado pelas Políticas do Ministério da Saúde. ${ }^{4}$ Entretanto, o presente serviço dispõe deste profissional apenas na unidade de PD, prevendo a implantação futura do TR nas unidades de internação.

Conforme mencionado, a partir das falas dos participantes foram criadas categorias de acordo com a análise proposta por Bardin. 0 Quadro 1 apresenta as categorias emergentes.

Quadro 1. Categorias e subcategorias provindas de familiares e profissionais acerca do suporte em saúde mental. Belo Horizonte, MG, 2018.

\begin{tabular}{|c|c|}
\hline Categoria & Subcategorias \\
\hline \multirow{2}{*}{$\begin{array}{l}\text { 1. Transtorno mental e } \\
\text { Adolescência }\end{array}$} & 1.1 Concepções sobre o transtorno mental para familiares e profissionais de saúde \\
\hline & 1.2 Causas e manifestações do transtorno mental \\
\hline \multirow[t]{2}{*}{ 2. Transtorno mental e família } & 2.1 O sentimento da família sobre o transtorno mental \\
\hline & 2.20 impacto do transtorno mental nos familiares \\
\hline \multirow{2}{*}{$\begin{array}{l}\text { 3. Tratamento oferecido ao } \\
\text { familiar no serviço }\end{array}$} & 3.1 Percepções dos familiares sobre o tratamento realizado no serviço \\
\hline & 3.2 Percepções dos profissionais sobre a inserção da família no serviço \\
\hline
\end{tabular}




\section{Transtorno mental e adolescência}

0 transtorno mental, com frequência, é incompreendido pelos familiares e até mesmo pelos profissionais de saúde. Nas subcategorias abaixo, foram abordadas as dificuldades dos familiares e profissionais em compreender essa temática, bem como, as manifestações e causas dessa doença no adolescente.

\subsection{Concepções de transtorno mental para familiares e profissionais de saúde}

Os familiares expressaram pouco entendimento sobre a concepção de transtorno mental, com isso, apresentam um sofrimento maior no seu cotidiano, uma vez que, pela falta de conhecimento e compreensão, são surpreendidos com os sintomas, a mudança de comportamento e as crises inerentes ao transtorno:

Eu acho que a pessoa, igual o caso dele é assim ele imagina as coisas ruins, pensa nas coisas ruins e às vezes ele acha que aquilo está acontecendo e fica nervoso com isso, o caso dele é esse. (F3)

Eu não sei explicar não [...] (F5)

Eu acho que é uma pessoa que está com a cabeça muito fraca, não tem condições de viver sozinho, de tocar a vida sozinho, sempre vai depender de mim e se ele depende de mim eu vou ter que viver para ele, em função dele. (F7).

A mesma pergunta também foi feita aos profissionais do serviço, com o intuito de conhecer suas percepções sobre o transtorno mental e pontuar a diferença de um conhecimento teórico consolidado para um conhecimento familiar baseado na vivência da doença:

Eu entendo que é uma pessoa que não se encontra em suas faculdades mentais normais, ela não está bem estruturada emocionalmente. (P1)

Todos os dias que eu me pego pensando sobre o transtorno infanto-juvenil isso me remete à questão da família, vulnerabilidade familiar que eu acho que é o que acontece mesmo, então isso potencializa os transtornos e quando você vai pesquisar, quando você vai avaliar mais profundamente você se esbarra em uma questão mais social. (P2) Eu percebo que hoje a saúde mental infanto-juvenil está muito ligada ao mundo contemporâneo, o estresse, o trabalho em excesso da família que muitas vezes a criança está há muito tempo passando por aquele transtorno mental e não é procurada ajuda né, às vezes falam: tem dois anos que meu filho está dentro de casa trancado. (P3)

\subsection{Causas e manifestações do transtorno mental}

Nas falas dos participantes, percebe-se que o transtorno mental muitas vezes foi associado a algum acontecimento no âmbito familiar, como um trauma, uma perda, uma decepção, ou seja, muitos familiares associam o aparecimento da doença a algum aspecto social relevante.

As manifestações são percebidas pela família por meio da mudança de comportamentos, humor, personalidade e atitudes do adolescente. 0 que é explicitado nas falas:

E o meu filho fica com isso na cabeça, porque eu mais o pai dele somos separados e o pai dele saiu de casa. Depois disso ele piorou, aí ele pensa que a culpa é minha, mas não é. (F7)

Quando ela dá a crise, ela fica pegando faca, falando que vai matar nós, por que eu sou separada do ex-marido meu [...] o pai dela estuprou ela e ela não esquece o pai. (F8)

Ela deu um surto, ela começou é [...] Deu os sintomas né, ficava no cantinho dela só lendo a Bíblia, depois foi perdendo o interesse pelas coisas e por tudo. Aí depois ela parou de falar, depois ela não queria alimentar mais falando que iria morrer não queria tomar mais água, tomar mais suco. Dizia que a presença dela no cemitério faria com que a família se unisse sobre seu túmulo. (F9)

\section{Transtorno mental e família}

0 transtorno mental tende a gerar sentimentos negativos nos familiares, sendo assim, as seguintes subcategorias explicitam os sentimentos em relação ao transtorno e o impacto da doença nos familiares.

\subsection{Sentimento da família sobre o transtorno mental}

0 transtorno mental gera um sentimento inexplicável nos familiares, como dificuldades em expressar os sentimentos advindos da doença, sendo comuns emoções negativas:

Eu fico muito triste né, eu queria que ele melhorasse e às vezes quando ele fica muito agitado muito nervoso, eu tenho medo dele. (F3)

Sentimento? Nossa me machucou demais. (choro) É isso, tristeza... Ah isso aí, não dá para falar não. É que dói né, você ver a pessoa que você ama desta forma né. (F4)

Quando eu vejo ele pegando uma faca, eu fico meio assim insegura. Será que isso vai acontecer de novo, vai se repetir? Sabe eu fico triste, eu não pensava que ele ia ter este caso.(F5) 
[...] Eu já sofri demais com esse menino, eu já me acabei de tanto sofrer com ele [...] ele fica três dias sem tomar banho e se eu for falar ele acha ruim comigo, ele quer bater no avô dele, ele xinga nós de tudo quanto é nome, briga na rua se deixar $[. .$.$] (F6)$

[...] Eu me sinto muito mal, muito mal mesmo, a gente acha que vai acontecer com todo mundo, menos com você [...]. É uma sensação de medo, de muita tristeza você vê seu filho, você criar ele e acontecer isso e você não poder fazer nada[...].(F7)

\subsection{Impacto do transtorno mental nos familiares}

A presença de uma pessoa com transtorno mental produz um impacto muito grande nas relações sociais, emocionais e financeiras dos seus cuidadores. Frequentemente, é preciso que familiares deixem de realizar suas atividades diárias para cuidar da pessoa com doença mental, abrindo mão de seus sonhos para viver em função do seu ente, o que fragiliza a família emocionalmente, podendo gerar mais dificuldades no cuidado do familiar e colocá-lo em um processo de adoecimento que também demanda assistência em saúde:

Eu saí do serviço por causa dela, tem mais de um ano. (F1)

Eu arrumava minhas unhas, eu arrumava o meu cabelo e não arrumo mais, não faço nada, para mim nada mais tem graça, não acho mais nada bonito. (F6)

Moramos em Mário Campos '(interior de Minas Gerais). Nós viemos para cá para ver se trocava os remédios e com isso eu estou sem trabalhar. Eu tinha uma expectativa de vida muito diferente, sonhos que hoje eu vejo que [...] (choro). (F7)

Isso arrebentou com a gente, tirou o nosso chão, a irmãzinha dela só fica chorando e com isso aí a gente fica sem chão sabe, sem chão, sem estrutura. (F9)

\section{3. $\quad$ Tratamento oferecido ao familiar pelo serviço}

Uma boa relação entre serviço e familiares tem sido de extrema importância, atendendo não só a necessidade da pessoa com doença mental, mas também, a demanda e necessidade dos familiares, que devido à sobrecarga e suas peculiares responsabilidades podem estar fragilizados, assim como a pessoa com uma doença, de um atendimento especializado pela equipe de saúde, seja por meio de psicoterapia breve e acompanhamentos (individual ou em grupo).

\subsection{Percepção dos familiares sobre ao tratamento ofertado no serviço}

Os familiares revelaram que não receberam nenhum atendimento oferecido pelo serviço, a não ser as reuniões direcionadas para familiares de adolescentes em PD ou conversas informais, quando necessário. Nas unidades de internação, os familiares que acompanham os adolescentes geralmente participam de atendimentos que ocorrem apenas no momento da internação, assim não dispõem da assistência de forma continuada durante a internação:

Não comigo. Até hoje não teve não, a psicóloga até falou: se quiser conversar comigo, tudo bem, mas especificamente para os pais mesmo, no meu caso eu não sei se tem, talvez até tenha, mais realmente não tenho conhecimento sobre isso. [...] eu acho bom né, igual no meu caso como estou falando eu fico meio perdida. (F1)

Não, só a ele mesmo. (F5)

Não. $O$ atendimento que tem para nós é a psicóloga que de vez em quando conversa com a gente muito pouquinho. Elas de vez em quando fazem uma reunião com todo mundo, mas assim, da primeira vez é bom, mas depois fica aquela coisa muito repetitiva. (F7)

Igual agora mesmo a médica viu o jeito que ele estava, a crise que ele estava aqui agora, coisa que ele nunca fez. Igual eu falei com ela, que ele estava tentando cortar o pulso do nada. Aí ela disse: na hora da consulta a gente conversa e saiu andando. Estou desesperada. (F7)

Observa-se no relato do F7, a explícita necessidade e postergação de um atendimento profissional, no momento da crise psicótica do adolescente. Após os familiares relatarem que não recebiam atendimentos específicos, também mencionaram sobre os desejos de receber algum tipo de assistência no serviço:

Eu gostaria que estivesse sim alguma coisa para nós, porque a cabeça melhora, a gente conversa com um conversa com o outro e distrai um pouco né[...]. (F6)

Eu acho que isso é de acompanhante para acompanhante, talvez um entretenimento que eles gostam de fazer, até mesmo de artesanato, oficinas, bordados para as mulheres que gostam. (F4)

Em contraposição, os profissionais mencionaram sobre os tipos, a frequência, o profissional que atende os familiares e as barreiras, como falta de recursos e envolvimento do familiar: 
A gente atende a família. Nós temos reuniões nas terças feira comigo e nas quintas com a outra psicóloga né, e as oficinas às vezes são dadas pelo TO e os pais participam. (P1)

É realizada uma reunião todos os dias, onde tanto os familiares quanto os pacientes são ouvidos né, tem a psicóloga que também tem uma oficina onde os familiares se envolvem. Tem também a escuta. Na medida que surge a demanda são realizadas as escutas. As oficinas a gente se esbarra com o fator de recursos, verba, aí tem que usar a criatividade. Mas acaba sendo muito difícil, por causa dessa falta de recurso, oferecer uma oficina; para os adolescentes já é difícil, para a família é ainda mais, mas quando eles se propõem a participar não tem problema nenhum, eles participam. (P2)

O familiar é acompanhado por toda a equipe, pelo serviço social, pela psicologia, pela terapêtica ocupacional, pela enfermagem, o médico também sempre procura atender a família, tem as reuniões dos pais, a reunião matutina todos os dias. Então a gente tenta estar sempre envolvendo a família ao máximo. (P3)

Apesar da ausência de atendimento direcionado aos familiares, de acordo com a percepção dos mesmos, há muita satisfação com o serviço em relação ao tratamento oferecido ao adolescente em crise:

Eu não tenho nada a reclamar não, o atendimento é muito bom eles são muitos atenciosos com ela. (F1)

Aqui é bom! Graças a Deus o tratamento é bom né, eu gosto de todo mundo aqui sabe. (F6)

Olha aqui é muito bom, não tenho nada que reclamar deles. (F7)

3.2 Percepção dos profissionais sobre a inserção da família no serviço.

Os profissionais percebem com grande importância a participação da família no tratamento do seu ente com transtorno mental. Considerando a necessidade de tratamentos mais humanizados para indivíduos em sofrimento psíquico, não só a pessoa com doença mental é vista como parte do processo, mas a família também se interpõe como parte essencial deste processo de reinserção social e bem-estar psicossocial:

Eu acho fundamental, até porque esses pacientes não podem estar desacompanhados e os pais são responsáveis por esses adolescentes, então eu acho muito importante que as famílias estejam presentes. (P1)

É de extrema importância a família estar presente no tratamento do adolescente, porque se ofamiliar estiver próximo, estiver presente isso vai ajudar o adolescente a se estabilizar no meio social, a aderir melhor ao tratamento. (P2)

A família é fundamental, né, se não tiver a família é muito difícil que o adolescente consiga construir isso sozinho, tem caso sim que a gente lida com jovens abrigados, que não tem família nenhuma ou que estão afastados das famílias e a gente percebe um dificultador no processo de melhora. Eles se sentem angustiados e acabam procurando uma pessoa para conseguir ter aquele suporte. Então assim, a família ela ajuda demais ela tem que estar junta, tem que estar presente. (P3)

\section{DISCUSSÃo}

0 estudo mostra que a maior parte da sobrecarga tem sido de responsabilidade do familiar do sexo feminino. Isso pode estar ocorrendo pelo fato do casal ser separado ou porque é preciso que um abra mão da sua vida social para viver em função do familiar doente e, neste caso, o pai precisa manter o emprego para o sustento da família. Nesse ínterim, fica claro que a "responsabilidade pela renda" ainda está associada ao gênero masculino e a "responsabilidade pelos cuidados" é do gênero feminino. No caso da ausência do suporte masculino, cabe estritamente à mulher a geração de renda e manutenção dos cuidados, o que aumenta, ainda mais, tal sobrecarga 22 .

0 cuidado está diretamente ligado ao feminino por uma razão adicional que se refere à diferenciação entre o princípio masculino e o feminino. Historicamente, os papeis da mulher e do homem são distintos. À mulher cabe a área reservada, sendo essa considerada frágil e "do lar" e sua ética se expressa pela fidelidade ao marido, pela reprodução e responsabilidade no desenvolvimento do filho. No entanto, ao homem cabe a área pública, e sua respeitabilidade resulta da capacidade de fornecer à família alimentos e respeito 22,23 .

Isso mostra que ainda é vigente a concepção de que a mulher nasce com um saber sobre o cuidar, o qual não cabe ao universo masculino. Cada vez mais, o hábito tradicional e cultural do cuidado da casa e dos filhos está associado à mulher e cabe ao homem o sustento financeiro familiar que está em processo de mudança ${ }^{22}$.

Entre os fatores de vulnerabilidade está o histórico prévio de doença mental na família, que pode estar associado à ocorrência de transtorno mental em outros familiares. 
Evidências ${ }^{2,4,24}$ de longa data mostram o caráter hereditário e/ou genético do adoecimento mental.

Além dos fatores genéticos, os aspectos inerentes ao próprio indivíduo (capacidade de enfrentamento a aspectos negativos, impulsividade e uso de substâncias psicoativas) estão associados a uma manifestação mais precoce do adoecimento mental.

Aspectos sociais e econômicos também interferem no desencadeamento ainda na adolescência. Estudos mostraram que a situação socioeconômica familiar precária e a baixa escolaridade dos pais e/ou responsáveis foram associadas significativamente a comportamentos de saúde mais fragilizados, tais como: alimentação inadequada, dificuldade de acesso a serviços de saúde, vivência em ambientes violentos e pouco seguros, uso de substâncias psicoativas, problemas emocionais e psicológicos ${ }^{2,25}$.

0 transtorno mental significa mais do que um conjunto de sintomas, pois possui outras representações de ordem simbólica, moral, social ou psicológica para o doente e a família. A família carece de conhecimento sobre sinais, sintomas e efeitos da doença de seu familiar e, apresentam dificuldades no momento de discutir sobre o assunto. Quando as famílias compreendem o sofrimento psíquico enfrentado pelo seu familiar, elas possuem mais capacidade de enfrentamentos para o manejo dos problemas relacionados à doença, com autonomia e segurança e menos sofrimento ${ }^{26}$.

Conforme apresentado nas falas, os familiares se sentem na obrigação de direcionar grande parte de seu tempo, abrindo mão do seu cotidiano para cuidar do seu ente. Além da dor, para muitos familiares, o transtorno mental é compreendido como motivo de vergonha. Na maioria dos casos, isso pode estar ocorrendo pela carência de conhecimentos mais qualificados sobre o transtorno mental por parte dos familiares ${ }^{26}$.

Comumente, os familiares possuem dificuldades de expressar suas ideias de forma clara e o entendimento sobre a doença mental. Apresentaram muitas dificuldades em falar sobre suas percepções sobre o transtorno mental, tendo em vista os relatos das experiências diárias sobre o adoecimento do adolescente, o que pode estar implícito o seu sofrimento enquanto familiar cuidador. Assim, percebe-se que o sofrimento é superior ao conhecimento acerca da doença, o que dificulta a identificação dos primeiros sinais e sintomas de uma crise, implementação de ações de prevenção e de intervenção sob orientação da equipe ${ }^{10}$.

Assim, reconhece-se, nas características preocupantes reveladas, que os familiares e os profissionais de saúde apresentam dificuldade em descrever e conceituar de maneira clara o fenômeno do adoecimento psíquico infanto-juvenil. No relato dos profissionais, pode ser notado que a maioria dos adolescentes são provenientes de famílias disfuncionais com elevados níveis de vulnerabilidade biopsicossocial. Evidências mostram que os adolescentes que vivenciam dificuldades no relacionamento familiar, como discussões entre pais e familiares, a separação dos responsáveis, pais usuários de álcool e/ou drogas e o baixo suporte emocional durante a infância, apresentam mais chance de desenvolver problemas de saúde mental em relação àqueles que tiveram boa comunicação no âmbito familiar 27,28.

Os relatos dos profissionais sugerem que o fator social tem implicações importantes no desencadeamento do transtorno mental entre os adolescentes. É comum que tais problemas emerjam das crises, na maioria das vezes após um acontecimento pessoal negativo, de grande impacto emocional e/ou psicológico no indivíduo ${ }^{10,26}$.

0 desentendimento familiar, situações que envolvem agressões verbais e físicas, as brigas, são fatores que contribuem para o desencadeamento do sofrimento psíquico em adolescentes. A relação familiar é a base para o desenvolvimento emocional do adolescente, ainda mais para aquele em sofrimento psíquico, tanto para prevenção de uma crise, quanto para manutenção e recuperação ${ }^{28}$.

As avaliações reportadas pelos familiares dos adolescentes que sofrem de transtorno mental ocorreram por meio da observação na mudança de comportamento desse adolescente, 
indicando atitudes consideradas como critérios diagnósticos do transtorno mental, como irritação, nervosismo, inquietação, isolamento, agitação e agressividade ${ }^{10,26}$.

Os relatos como mudanças bruscas de humor e/ou comportamento podem ser confundidos e ignorados pelos familiares. Parte dos sinais e sintomas iniciais de um desencadeamento remetem às alterações e instabilidades inerentes à adolescência, o que confunde o observador, fazendo parecer uma simples manifestação mais excessiva dessa fase de vida ${ }^{26,27}$. Ademais, alguns sinais foram manifestados desde a infância desse indivíduo, não sendo percebido pela família com estranheza, mas assumindo um traço de naturalidade da personalidade, o que dificulta o diagnóstico e acompanhamento do agravamento da sintomatologia27.

A doença mental, assim como qualquer outra doença crônica, afeta profundamente não só o doente, mas também todo o núcleo familiar. Percebe-se que a angústia está presente em todos os familiares entrevistados, atingidos profundamente pelo sofrimento, sentimento presente em todos os aspectos de suas vidas, tornando-se o companheiro de todas as horas, ao longo da trajetória do familiar doente. Os sentimentos manifestam-se de várias formas e intensidades, deixando profundas marcas na vida dos familiares ${ }^{17}$.

No momento da crise, os portadores de sofrimento psíquico podem apresentar episódio de agressividade, causando angústia, insegurança, tristeza e medo como citado nos relatos dos familiares. Sendo assim, esse é o momento que a relação da família com o adolescente portador do transtorno mental tende, então, a ser mais dramática, pois os indícios são mais intensos e ameaçadores à segurança do grupo familiar e do próprio adolescente. 0 medo de sofrer uma agressão e a tensão relacional faz com que o familiar tenha a necessidade de estar sempre vigilante para que o adolescente não coloque a própria vida ou a de terceiros em risco, o que agrava a sobrecarga do cuidador ${ }^{24}$.

A convivência com o familiar com transtorno mental provoca sobrecarga caracterizada por dificuldades como: problemas no relacionamento com o familiar portador da doença, estresse por conviverem com o humor instável do doente e a dependência do portador de sofrimento psíquico, bem como o medo das recaídas e do comportamento inesperado do doente no período das crises ${ }^{12,25}$.

Os familiares podem passar por diferentes estágios no enfrentamento do processo de adoecimento, desde a aceitação e compreensão do transtorno até um sentimento de impotência e insegurança, por não conseguirem resolver o problema do jovem adoecido. Esse último aspecto faz com que o familiar cuidador também entre em sofrimento, podendo adoecer conjuntamente, sendo a depressão e os transtornos de ansiedade os problemas mais comuns ${ }^{24}$.

0 transtorno mental não reflete apenas na vida do indivíduo doente, mas reflete na vivência do grupo familiar, uma vez que cada um dos familiares interpreta e mobiliza sentimentos de forma diferente e única. A doença constitui-se um evento adverso e inesperado que desorganiza a maneira de ser e viver da família, exigindo novo método e adaptação à nova situação $0^{9,26}$.

A não remissão dos sintomas, os fracassos sociais e o comportamento anormal do familiar com transtorno mental colaboram para o surgimento de tensões e sofrimento no núcleo familiar, isso altera sua rotina diária9 . Diante da sobrecarga e sofrimento dos familiares, é preciso que o familiar desenvolva recursos simbólicos para enfrentar esse adoecimento, o que ressalta a importância do serviço de acolhimento e de cuidado para esse cuidador.

A portaria 224/92 recomendava o atendimento do familiar como uma das atividades a serem desenvolvidas pelos profissionais da saúde mental. A portaria 336/2002 que regulamenta os Centros de Atenção Psicossocial (CAPS) associa o atendimento à família entre as ações a serem efetuadas pelos profissionais de saúde, e a Portaria 251/2002 que estipula diretrizes e normas para assistência em hospital psiquiátrico, inclui programas próprios e interdisciplinares visando ao tratamento de acordo com a necessidade de cada usuário e de sua família ${ }^{29}$. Percebe-se que são várias as portarias que abordam a importância da inserção e de 
um atendimento voltado para os familiares. Existem programas próprios a serem realizados com esses indivíduos como oficinas, grupos operativos ou de conversa, atendimentos individuais com o técnico de referência, entre outros.

Diversas são as modalidades terapêuticas voltadas à família, intervenções diretas (manejo comportamental centrado na família ou terapia familiar) com envolvimento mais imediato da família e que possuem objetivos específicos a serem trabalhados durante um período de tempo. Já as intervenções indiretas (terapia psicodinâmica ou terapia cognitivocomportamental) incorporam a percepção da família como informantes do processo familiar ${ }^{14}$. Existem diferentes abordagens da família, mas sua utilização depende da formação do profissional e do contexto, sendo as intervenções psicoeducativas, comportamentais e a terapia familiar sistêmica as mais utilizadas ${ }^{14,30}$.

As ações dirigidas à família de portadores de sofrimento psíquico devem estruturar-se de modo a beneficiar e fortalecer a relação profissional/familiar/serviço, entendendo-se que os familiares são fundamentais no tratamento do adolescente portador de transtorno mental ${ }^{14,28}$. No entanto, nas falas dos participantes observou-se diferenças entre as percepções dos familiares e dos profissionais, o que sugere que as atividades desenvolvidas para os familiares não são frequentes ou que o objetivo ou desenvolvimento das mesmas não está claro para os acompanhantes.

Nos relatos, foi observada a carência que os familiares têm de um atendimento exclusivo, o que acontece com pouca frequência no serviço. Nesse sentido, torna se importante destacar que o processo de construção do plano terapêutico deve envolver o sujeito doente e seu familiar e relevar sua situação social e biográfica. Nesse sentido, é importante que os profissionais reconheçam a família como alvo de cuidados, que precisa de apoio para a normalização da sua rotina familiar ${ }^{29,30 .}$

O envolvimento da família no processo terapêutico torna as intervenções mais eficientes, aumenta os recursos ao paciente, em especial sua adesão ao tratamento. Por ser a família fator importante na proteção da saúde ou na manifestação da doença, é necessário capacitar profissionais para que esses possam reconhecer as necessidades das famílias e darlhes a devida escuta e atenção ${ }^{5,9,17}$.

A família, no processo de trabalho, é um elemento indispensável, quando se pensa o redimensionamento da assistência em saúde mental. A reabilitação psicossocial não se limita apenas ao uso de psicofármacos e intervenções, mas também a ações e a procedimentos que visem à reintegração familiar, social e profissional e melhoria na qualidade de vida do doente mental e seu entorno ${ }^{29}$.

\section{CONCLUSÃO}

A doença mental traz impactos emocionais, físicos e financeiros nos familiares e leva a mudanças de rotina para promover o cuidado da pessoa em sofrimento. Sendo assim, percebese a necessidade de um tratamento direcionado ao familiar para aliviar as angústias decorrentes do transtorno mental do familiar em tratamento, fazendo-se necessárias ações e atendimentos mais sistemáticos e frequentes a esses familiares, uma vez que presença da família é fundamental no processo terapêutico do adolescente.

Dentre as limitações do estudo, destacam-se as peculiaridades da amostra de adolescentes e as do local em que o estudo foi realizado, uma vez que a pesquisa foi desenvolvida somente com adolescentes internados ou em permanência dia, não contemplando os adolescentes em acompanhamento ambulatorial. Assim, os resultados devem ser avaliados com cautela. No entanto, esse estudo é importante para repensar a dinâmica de atendimento familiar na instituição participante. 


\section{REFERÊNCIAS}

1. Savage JE, Rose RJ, Pulkkinen L, Silventoinen K, Korhonen T, Gillespie N, et al. Early maturation and substance use across adolescence and young adulthood: a longitudinal study of Finnish twins. DevPsychopathol. [Internet]. 2017 [citado em 21 fev 2020]; 30(1):79-92. DOI: $10.1017 / \mathrm{s} 0954579417000487$

2. World Health Organization. Health for the World's adolescents: a second chance in the second decade [Internet]. Geneva: WHO; 2014 [citado em 21 fev 2020]. Disponível em: https://www.who.int/maternal_child_adolescent/documents/second-decade/en/

3. Sawyer SM, Afifi RA, Bearinger LH, Blakemore SJ, Dick B, Ezeh AC, et al. Adolescence: a foundation for future health. Lancet [Internet]. 2012 [citado em 21 fev 2020]; 379(1):1630-40. DOI: 10.1016/s01406736(12)60072-5

4. Organização Mundial da Saúde. OMS: 1 em cada 5 adolescentes enfrenta problemas de saúde mental [Internet]. Brasília, DF: OMS Brasil;2018 [citado em 21 fev 2020]. Disponível em: https://nacoesunidas.org/oms-1-em-cada-5-adolescentes-enfrenta-problemas-de-saude-mental/ 5. Martín Gutiérrez R, Payá González B. Las Psicosis de inicio temprano: una revisión. Rev Psiquiatr

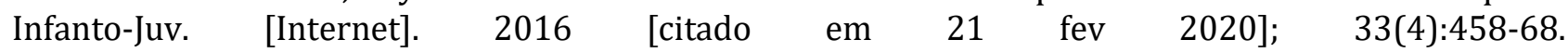
DOI: https://doi.org/10.31766/revpsij.v33n4a2

6. Trotman HD, Holtzman CW, Ryan AT, Shapiro DI, MacDonald AN, Goulding SM, et al. The development of psychotic disorders in adolescence: a potential role for hormones. Horm Behav. [Internet]. 2013 [citado em $21 \mathrm{fev} 2020$ ]; 64(2):411-9. DOI: 10.1016/j.yhbeh.2013.02.018

7. Jaworska N, MacQueen G. Adolescence as a unique developmental period. J Psychiatry Neurosci. [Internet]. 2015 [citado em 21 fev 2020]; 40:291-3. DOI: 10.1503/jpn.150268

8. Rodríguez-Meirinhos A, Antolín-Suárez L, Oliva A. Support needs of families of adolescents with mental illness: a systematic mixed studies review. Arch PsychiatrNurs. [Internet]. 2018 [citado em 21 fev 2020]; 32:152-63. DOI: https://doi.org/10.1016/j.apnu.2017.09.004

9. Huang L, Stroul B, Friedman R, Mrazek-Rochester P, Friesen B, Pires S, et al. Transforming mental health care for children and their families. AmPsychol. [Internet]. 2005 [citado em 21 fev 2020]; 60: 61527. DOI: $10.1037 / 0003-066$ X.60.6.615

10. Martins PPS, Guanaes-Lorenzi C. Participação da família no tratamento em saúde mental como prática no cotidiano do serviço. Psicol Teor Pesqui. [Internet]. 2016 [citado em 21 fev 2020]; 32(4):1-9. DOI:10.1590/0102.3772e324216

11. Fernandes CSNNN, Nóbrega MPSS, Angelo M, Torre MI, Chaves SCS. Importância das famílias nos cuidados à pessoa com transtorno mental: atitudes de enfermeiros. Esc Anna Nery Rev Enf. [Internet]. 2018 [citado em 21 fev 2020]; 22(4):1-8. DOI: 10.1590/2177-9465-EAN-2018-0205 12. Bademli K, Duman ZC. Effects of a family to family support program on mental health and coping strategies of caregivers of adults with mental illness: a randomized controlled study. ArchPsychiatrNurs. [Internet]. 2014 [citado em $21 \mathrm{fev} 2020$ ]; 28:392-8. DOI: 10.1016/j.apnu.2014.08.011

13. Silva EM, Jorge MSB, Queiroz MVO. Perspectiva da família na convivência com o ser portador de esquizofrenia. Rev Rene [Internet]. 2016 [citado em 21 fev 2020]; 4(2):53-60. Disponível em: http://periodicos.ufc.br/rene/article/view/5698/4085

14. Jiménez L, Hidalgo V, Baena S, León A, Lorence B. Effectiveness of Structural-Strategic Family Therapy in the treatment of adolescents with mental health problems and their families. InterJEnvironResPublic Health [Internet]. 2019 [citado em 21 fev 2020];16(7):1-14. DOI: $10.3390 /$ ijerph16071255

15. Brasil. Lei Federal 10.216 de 06 de abril de 2001. Dispõe sobre a proteção e os direitos das pessoas portadoras de transtornos mentais e redireciona o modelo assistencial em saúde mental [Internet]. Brasília, DF; 2001 [citado em 21 fev 2020]. Disponível em: http://www.planalto.gov.br/ccivil_03/leis/leis_2001/110216.htm

16. Ministério da Saúde (Br). Atenção psicossocial a criança e adolescente no SUS: tecendo redes para garantir direitos [Internet]. Brasília, DF;2014 [citado em 21 fev 2020]. Disponível em: http://bvsms.saude.gov.br/bvs/publicacoes/atencao_psicossocial_criancas_adolescentes_sus.pdf 17. Eassom E, Giacco D, Dirik A, Priebe S. Implementing family involvement in the treatment of patients with psychosis: a systematic review of facilitating and hindering factors. BMJ Open [Internet]. 2014 [citado em 21 fev 2020]; 4(10):1-12. DOI: 10.1136/bmjopen-2014-006108 18. Oliveira RMP, Loyola CM. Família do paciente psiquiátrico: o retrato de uma ilustre desconhecida. 
Acta Sci, Health Sci. [Internet]. 2004 [citado em 21 fev 2020]; 26(1):213-22. DOI: 10.4025/actascihealthsci.v26i1.1679

19. Gil AC. Como elaborar projeto de pesquisa.5ed. São Paulo: ATLAS S.A.; 2010. 184 p.

20. Fontanella BJB, Ricas J, Turato ER. Amostragem por saturação em pesquisas qualitativas em saúde: contribuições teóricas. Cad Saúde Públ. [Internet]. 2008 [citado em 21 fev 2020]; 24(1):17-27. DOI: 10.1590/S0102-311X2008000100003

21. Bardin L. Análise de conteúdo. Pinheiro LA, tradutor. São Paulo: Edições 70; 2016.

22. Guedes OS, Daros MA. O cuidado como atribuição feminina: contribuições para um debate ético. Serv Soc Rev. [Internet]. 2009 [citado em 21 fev 2020]; 12(1):122-34. DOI: 10.5433/16794842.2009v12n1p122

23. Duarte RA. Configurações familiares e papel da mulher na política de saúde mental no Brasil. Gênero [Internet]. 2015 [citado em 21 fev 2020]; 16(1):155-78. DOI: 10.22409/rg.v16i1.750

24. Apter G, Bobin A, Genet MC, Gratier M, Devouche E. Update on mental health of infants and children of parents affected with mental health issues. Curr Psychiatry Rep. [Internet]. 2017 [citado em 21 fev 2020]; 19(10):72. DOI: 10.1007/s11920-017-0820-8

25. World Health Organization. The health and social effects of nonmedical cannabis use [Internet]. Geneva: WHO; 2016 [citado em 21 fev 2020]. Disponível em: https://www.who.int/substance_abuse/publications/msbcannabis.pdf

26. Pereira MAO, Pereira JA. Transtorno mental: dificuldades enfrentadas pela família. RevEscEnferm USP [Internet]. 2003 [citado em 21 fev 2020]; 37(4):92-100. DOI:101590/S0080-62342003000400011 27. Avanci JQ, Assis SG, Oliveira RVC, Ferreira RM, Pesce RP. Fatores associados aos problemas de saúde mental em adolescentes. Psicol Teor Pesq. [Internet]. 2007 [citado em $21 \mathrm{fev}$ 2020]; 23(3):287-94. DOI: 10590/S0102-37722007000300007

28. Thiengo DL, Cavalcante MT, Lovisi GM. Prevalência de transtornos mentais entre crianças e adolescentes e fatores associados: uma revisão sistemática. J Bras Psiquiatr. [Internet]. 2014 [citado em 21 fev 2020]; 63(4):360-72. DOI: 10590/0047-2085000000085 29. Ministério da Saúde (Br). Legislação em saúde mental: 1990-2004 [Internet]. Brasília, DF: Ministério da Saúde; 2004 [citado em 21 fev 2020]. Disponível em: http://bvsms.saude.gov.br/bvs/publicacoes/legislacao_saude_mental_1990_2004_5ed.pdf 30. Lebow JL, Stroud CB. Family therapy. New York: American Psychological Association; 2016.

\section{CONTRIBUIÇÕES}

Ingrid Moreira dos Santos e Belisa Vieira da Silveira contribuíram na concepção e desenho da pesquisa, coleta e análise dos dados e, redação. Adaene Alves Machado de Moura e Sandra Cristina Pillon atuaram na análise dos dados, redação e revisão.

\section{Como citar este artigo (Vancouver)}

Santos IM, Silveira BV, Moura AAM, Pillon SC. Percepção da família acerca do suporte profissional recebido em um serviço de saúde mental infanto-juvenil. REFACS [Internet]. 2020 [citado em inserir dia, mês e ano de acesso]; 8(Supl. 1):512-523. Disponível em: inserir link de acesso. DOI: inserir link do DOI.

\section{Como citar este artigo (ABNT)}

SANTOS, I. M.; SILVEIRA, B. V.; MOURA, A. A. M.; PILLON, S. C. Percepção da família acerca do suporte profissional recebido em um serviço de saúde mental infanto-juvenil. REFACS, Uberaba, MG, v. 8, p. 512-523, 2020. Supl. 1. Disponível em: inserir link de acesso. Acesso em: inserir dia, mês e ano de acesso. DOI: inserir link do DOI.

\section{Como citar este artigo (APA)}

Santos, I.M., Silveira, B.V., Moura, A.A.M., \& Pillon SC (2020). Percepção da família acerca do suporte profissional recebido em um serviço de saúde mental infanto-juvenil. REFACS, 8(Supl. 1), 512-523. Recuperado em: inserir dia, mês e ano de acesso de inserir link de acesso. DOI: inserir link do DOI. 